\title{
Investigation of factors associated with low adherence to treatment of codependency in family members of psychoactive substance users
}

\author{
Investigação de fatores associados à baixa adesão ao \\ tratamento da codependência de familiares \\ de usuários de substâncias psicoativas
}

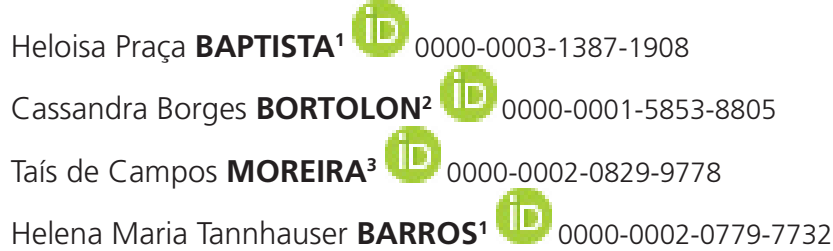

\begin{abstract}
The aim of this study was to investigate possible factors that prevent adherence to the treatment of codependent family members of problem drug use individuals. A quasi-experimental study was carried out with 133 relatives of psychoactive substances users who called the Brazilian drug hotline (Ligue 132) between 2013 and 2015, from the five regions of Brazil. The following instruments were used: General service protocol; Family assistance protocol; Holyoake Codependency Index; Behavioral Adherence Scale; and Adherence Factor Questionnaire. Univariate analysis of data was performed for categorical variables and Chi-square test for comparison between variables, with $p<0.05$. The sample showed a predominance of women (91.7\%), especially mothers (82.7\%). Among the investigated factors, alcohol as the substance involved in the problem showed a significant association with the non-adherence to treatment through teleintervention of family members.
\end{abstract}

Keywords: Codependency; Family relations; Patient compliance; Substance-related disorders; Telemedicine.

$\mathbf{v} \mathbf{v} \mathbf{v}$

${ }^{1}$ Universidade Federal de Ciências da Saúde de Porto Alegre, Departamento de Toxicologia e Farmacologia, Programa de Pós-Graduação em Ciências da Saúde. Porto Alegre, RS, Brasil.

2 Universidade Federal de São Paulo, Departamento de Psiquiatria, Programa de Pós-Graduação em Psiquiatria e Psicologia Médica. São Paulo, SP, Brasil.

${ }^{3}$ Hospital Moinhos de Vento, Setor de Responsabilidade Social. R. Ramiro Barcelos, 630, Floresta, 90035-001, Porto Alegre, RS, Brasil. Correspondence to: H.M.T. BARROS. E-mail: <helenbar@ufcspa.edu.br>.

Support: This study was done with the support of the Coordenação de Aperfeiçoamento de Pessoal de Nivel Superior (Funding Code: 001). Article based the dissertation of H.P. BAPTISTA, entitled "Adesão de familiares de usuârios de substâncias psicoativas ao acompanhamento por meio de telemedicina". Universidade Federal de Ciências da Saúde de Porto Alegre, 2018.

How to cite this article

Baptista, H. P., Bortolon, C. B., Moreira, T. C., \& Barros, H. M. T. (2021). Investigation of factors associated with low adherence to treatment of codependency in family members of psychoactive substance users. Estudos de Psicologia (Campinas), 38, e200023. https:// doi.org/10.1590/1982-0275202138e200023 


\section{Resumo}

O objetivo deste estudo foi investigar possiveis fatores impeditivos da adesão de familiares codependentes a um tratamento. Realizou-se um estudo quase experimental com 133 familiares de usuários de substâncias psicoativas que ligaram para o Ligue 132 no período de 2013 a 2015, sendo que a amostra tem representantes das 5 regiões do Brasil. Os instrumentos utilizados foram: Protocolo geral de atendimento; Protocolo de atendimento ao familiar; Holyoake Codependency Index; Escala de Adesão Comportamental e Questionário de Fatores sobre Adesão. Foram realizadas análises univariadas dos dados para as variáveis categóricas e teste Qui-quadrado para comparação entre as variáveis, $p<0,05$. A amostra apresentou o predomínio de mulheres $(91,7 \%)$ entre os familiares que buscaram ajuda, em especial de mães (82,7\%). Dentre os fatores investigados, notou-se que o álcool, entre as substâncias utilizadas pelos usuários, apresentou associação significativa com a não adesão dos familiares a tele intervenção.

Palavras-chave: Codependência; Relações familiares; Cooperação do paciente; Transtornos relacionados ao uso de substâncias; Telemedicina.

The report published by the United Nations Office on Drugs and Crime (2017), indicated that about 29.5 million people worldwide have a problem drug use. Brazil has more than 8 million people who use alcohol and/or other drugs (5.7\% of the population) (Laranjeira, Madruga, Pinsky, Caetano, \& Mitsuhiro, 2014). The use of psychoactive substances, in addition to causing significant losses in the user's life, generates negative and lasting effects on members of the family system, and there may be many people in distress living with this problem drug user (Ahmad-Abadi et al., 2017; Lima et al., 2019; Vederhus, Kristensen, \& Timko, 2019; Zielinski et al., 2019).

The suffering caused to family members is described in a similar way in different cultures; with symptoms of physical and psychological illnesses, changes in family relationships, situations of violence, and economic problems (Ahmad-Abadi et al., 2017; Askian, Krauss, Baba, Kadir, \& Sharghi, 2016; Bortolon et al., 2017; Lampis, Cataudella, Busonera, \& Skowron 2017; Panaghi, Ahmadabadi, Khosravi, Sadeghi, \& Madanipour, 2016; Tamutiene \& Laslett, 2016; Ulusoy \& Guçray, 2017). The need for treatment of family members is evidenced by the range of physical and psychological symptoms pointed out in numerous studies (Askian et al., 2016; Lima et al., 2019; Silva Oliveira, Silva, Algeri, \& Soares, 2019; Zielinski et al., 2019). Interventions directed to the specific demands of family members who are affected by the problem use of drugs of a loved-one are effective in reducing physical and psychological symptoms and the characteristic symptoms of codependency (Ahmad-Abadi et al., 2017; Bortolon et al., 2017).

The literature presents a wide range of definitions of codependency (Bortolon et al., 2017). However, there is no definition of diagnostic criteria for codependency. One of the definitions that is currently widely used, the one adopted in this study, proposes to describe codependency as the development of a set of dysfunctional behaviors and thoughts manifested by people (in general, fathers / mothers, spouses or children) related to their close relative who has a problem drug use of alcohol and other licit or illicit drugs, causing these family members significant psychological distress (Dear \& Roberts, 2005; Silva et al., 2019). According to this definition, codependency can be understood as an interrelation problem, which expresses a pattern of problem behaviors and thoughts learned among family members and psychoactive substance users (Bortolon et al., 2017). Research reports on codependency are still scarce, with most studies still focusing only on the user of psychoactive substances, not extending to family members who also suffer the consequences of use.

For all sick patients, whether users or family members, adherence is a primary factor, regardless of treatment (World Health Organization [WHO], 2003). This process is related to the patient's posture and commitment, in view of what has been agreed with the health care professional (Reiners, Azevedo, Vieira, \& Arruda, 2008). Adherence to treatment in the use of psychoactive substances is a complex and

2 challenging process for the health care team (Oene, Burger, Grobbee, \& Schrijvers, 2007). Low adherence 
leads to less efficacy in therapeutic processes and is measured by a high treatment dropout rate, both for users and their families (Moreira et al., 2014; WHO, 2003). The identification of factors of non-adherence to treatment facilitates the development of new strategies to increase the engagement of family members and, consequently, significant changes in their behavior, improving their quality of life and their capability to help the drug user himself.

The aim of this study was to investigate the factors that may interfere with adherence to a motivational intervention through telemedicine to decrease the codependency between family members and psychoactive substance users.

\section{Method}

\section{Participants}

The sample consisted of 133 codependent family members. We considered family members, parents, siblings, spouses, or people in a stable relationship, sons/daughters, grandparents, uncles, cousins, and nephews, over the age of 18 and who accepted to participate voluntarily after reading the Informed Consent Form. The protocols of family members of tobacco-only users, incomplete first-call protocols, and prank calls were excluded from the study, in addition to those family members who demonstrated difficulty in understanding the scales.

\section{Procedures}

A quasi-experimental study was carried out, of codependent family members, who asked for help in dealing with their family member who used licit or illicit drugs, through calls to the Brazilian drug hotline Ligue 132 (Dial 132). A telephone counseling service that offered free and anonymous information and guidance on drugs and problem drug use to the 5 regions of Brazil. This service was developed in the Universidade Federal de Ciências da Saúde de Porto Alegre (Federal University of Health Sciences of Porto Alegre) and funded by the Secretaria Nacional de Políticas Sobre Drogas (National Drug Policy Secretariat). Family members and psychoactive substance users who called the hotline were instructed on the characteristics of psychoactive substances, their acute and chronic effects and ways of preventing problem drug use in the society. Ligue 132 also provided information on treatment services available in each location, such as outpatient and recovery treatment centers and self-help groups for users and family members (Machado, Moreira, Ferigolo, Oliveira, \& Barros, 2012). The main complaints presented by family members who called the hotline was the mental health issues generated by the use of substances, the difficulties in the relationship with the user, and the lack of knowledge about the substance used by the individual (Bortolon et al., 2017).

The medical consultations and data collection were carried out by health care graduates who received previous and continued training in neurosciences, brief motivational intervention, chemical dependency, dealing with patients, and telephoning skills. The consultations were supervised by postgraduate health care professionals (Barros, Santos, Mazoni, Dantas, \& Ferigolo, 2008).

The family assistance protocol was structured as follows: family members who called the hotline had their initial demand met, and were later invited to participate in family monitoring and asked about their voluntary participation in studies of the codependency between family members and psychoactive substance users. Failure to participate in the studies did not influence this monitoring. Eight phone calls were scheduled with the family member to proceed with the intervention. Randomized family members in the control group 
had their demands met and received psychoeducation on psychoactive substances; the family members of the experimental group, on the other hand, received interventions based on the motivational interview and the trans-theoretical model of stages of change to meet their demands. Each call followed a structured protocol to assist the family in the preparation, action, and maintenance of changes in the behaviors of codependents (Bortolon et al., 2017).

Adherence was measured through the continuity of the family member in the six-month follow-up, by making eight pre-scheduled calls. Behavior changes by codependent family members, previously agreed with the health care professional, were also considered as a criterion for adherence in this study.

In the period from January 2013 to December 2015, 2,704 protocols for family connections were registered. Subsequently, these protocols were analyzed to constitute the sample of the present study. Data collection was performed with proactive calls, after the retroactive analysis of the protocols generated. For every protocol, at least three call attempts were made at different times before being excluded (Figure 1).

The study was submitted to and approved by the Research Ethics Committee of the Universidade Federal de Ciências da Saúde de Porto Alegre (Federal University of Health Sciences of Porto Alegre) protocol $n^{\circ} 2.035 .980$.

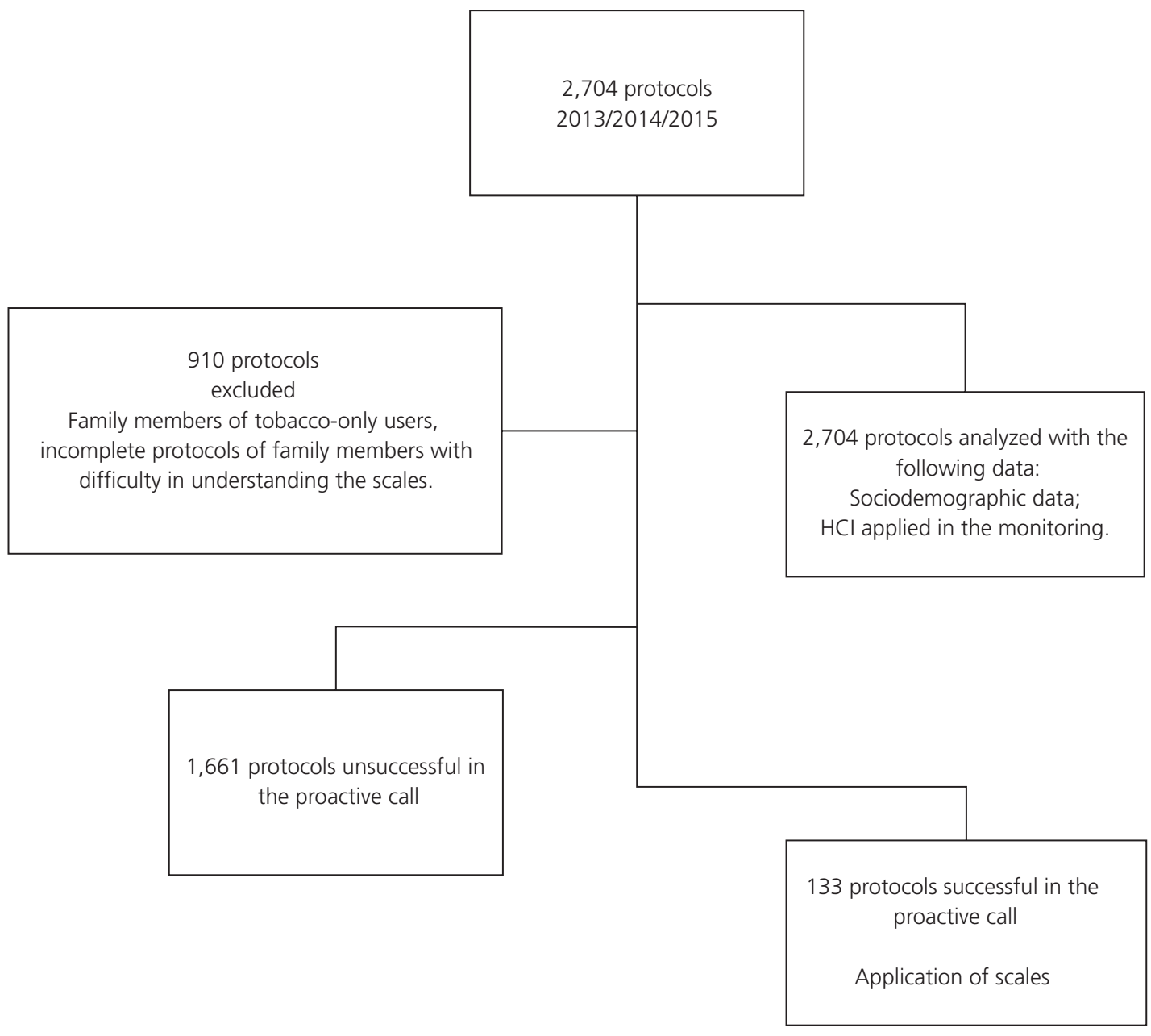

4 Figure 1. Flowchart of registered and analyzed protocols, and proactive connections. 


\section{Instruments}

The General Service Protocol, generated by the specific Ligue 132 software (which stored sociodemographic data), the Family Assistance Protocol (which included information related to the degree of relatedness with the user), use of psychoactive substance, and previous search for help (Bortolon et al., 2017).

To measure changes in behaviors of codependents, a translated and adapted version (Bortolon et al., 2017) of the Holyoake Codependency Index ( $\mathrm{HCl}$ ) scale (Dear \& Roberts, 2005) was used, which assesses the degree of beliefs and behaviors of codependents. The $\mathrm{HCl}$ consists of 13 items on a Likert-type scale showing a level of 5 points of agreement ranging from total agreement to total disagreement. The score ranges from 3 to 15 points (Dear \& Roberts, 2005). When the score was $\geq 9.7$ there was an indication of high codependency (Bortolon et al., 2017). Changes in behaviors of codependents were assessed by the identification of changes in the $\mathrm{HCl}$ scores. That is, those family members who had lower $\mathrm{HCl}$ scores during the calls, indicated an improvement in the behaviors of codependents. Therefore, it can be assessed that they adhered better to motivational teleintervention while they were making the calls.

The Behavioral Adherence Scale identified behavioral issues related to adherence to telephone monitoring. This scale was developed based on the Morisky Medication Adherence Scale used to measure medication adherence in hypertensive patients (Morisky et al., 2008; Oliveira-Filho, Morisky, Neves, Costa, \& Lyra, 2014), with a version validated to the Brazilian context (Oliveira-Filho et al., 2014).

The statistical analysis of data was performed using the IBM ${ }^{\circledR}$ SPSS ${ }^{\circledR}$ Statistics (version 19.0). Univariate analyzes were performed for categorical variables and comparisons between variables were performed using the Chi-square test, with $p<0.05$ considered statistically significant.

\section{Results}

The sample was predominantly female $(91.7 \%)$, aged 45 years or over $(70.0 \%)$, who sought help regarding the use of psychoactive substances for a male relative $(82.7 \%)$, aged 25 or over $(66.4 \%)$. Regarding the degree of relatedness, more than $65.0 \%$ of family members were mothers, followed by $13.5 \%$ of other members of the family system (uncle/aunt, cousin, and grandparent), and $9.8 \%$ of spouses. As for the consumption of psychoactive substances by the problem drug user family member, the prevalence of tobacco (23.3\%) was higher than alcohol (14.3\%), according to Table 1.

Table 1

Sociodemographic characteristics and health conditions of family members who answered the proactive call $n=133$

1 of 3

\begin{tabular}{lc}
\hline Variables & $N(\%)$ \\
\hline Sex of family members $(n=133)$ & $122(91.7 \%)$ \\
$\quad$ Female & $11(8.3 \%)$ \\
Male & \\
Family age $(n=127)$ & $89(70.1 \%)$ \\
$\geq 45$ years old & $38(29.9 \%)$ \\
$<45$ years old & \\
Degree of relatedness $(n=133)$ & $87(65.4 \%)$ \\
Mother & $8(6 \%)$ \\
Father & $13(9.8 \%)$ \\
Spouse & $6(4.5 \%)$ \\
Sibling & $1(0.8 \%)$ \\
Son/daughter & $18(13.5 \%)$ \\
Other & \\
\hline
\end{tabular}


Table 1

Sociodemographic characteristics and health conditions of family members who answered the proactive call $n=133$

\begin{tabular}{|c|c|}
\hline Variables & $N(\%)$ \\
\hline \multicolumn{2}{|l|}{ Profession $(n=128)$} \\
\hline Retired & $16(12.5 \%)$ \\
\hline Self-employed & $14(10.9 \%)$ \\
\hline Unemployed & $11(8.6 \%)$ \\
\hline Housewife / Househusband & $32(25 \%)$ \\
\hline Health care professional & $1(0.8 \%)$ \\
\hline Professional in other areas & $54(42.2 \%)$ \\
\hline \multicolumn{2}{|l|}{ Marital state $(n=128)$} \\
\hline Married & $71(55.5 \%)$ \\
\hline Separated & $25(19.5 \%)$ \\
\hline Single & $16(12.5 \%)$ \\
\hline Widowed & $16(12.5 \%)$ \\
\hline \multicolumn{2}{|l|}{ Family income $(n=127)$} \\
\hline Between 1 and 5 minimum wages & $80(63 \%)$ \\
\hline Between 5 and 10 minimum wages & $34(26.8 \%)$ \\
\hline More than 10 minimum wages & $13(10.2 \%)$ \\
\hline \multicolumn{2}{|l|}{ Educational level $(n=127)$} \\
\hline Illiterate & $1(0.8 \%)$ \\
\hline Incomplete Elementary School & $43(33.9 \%)$ \\
\hline Incomplete High School & $9(7.1 \%)$ \\
\hline Certificate program & $2(1.6 \%)$ \\
\hline Complete Elementary School & $17(13.4 \%)$ \\
\hline Complete High School & $38(29.9 \%)$ \\
\hline Incomplete Higher Education & $5(3.9 \%)$ \\
\hline Complete Higher Education & $12(9.4 \%)$ \\
\hline \multicolumn{2}{|l|}{ Family member uses drugs $(n=133)$} \\
\hline Yes & $44(33.1 \%)$ \\
\hline No & $89(66.9 \%)$ \\
\hline \multicolumn{2}{|l|}{ Family member drinks alcohol $(n=133)$} \\
\hline Yes & $19(14.3 \%)$ \\
\hline No & $114(85.7 \%)$ \\
\hline \multicolumn{2}{|l|}{ Family member smokes tobacco $(n=133)$} \\
\hline Yes & $31(23.3 \%)$ \\
\hline No & $102(76.6 \%)$ \\
\hline \multicolumn{2}{|c|}{ Family member consumes cocaine $(n=133)$} \\
\hline Yes & $1(0.8 \%)$ \\
\hline No & $132(99.2 \%)$ \\
\hline \multicolumn{2}{|c|}{ Type of health problem reported $(n=133)$} \\
\hline Physical & $26(29.5 \%)$ \\
\hline Psychological & $46(52.3 \%)$ \\
\hline Both & $16(18.2 \%)$ \\
\hline \multicolumn{2}{|l|}{ Depression $(n=133)$} \\
\hline Yes & $39(53.4 \%)$ \\
\hline No & $34(46.6 \%)$ \\
\hline \multicolumn{2}{|l|}{ Anxiety $(n=133)$} \\
\hline Yes & $9(12.3 \%)$ \\
\hline No & $64(87.7 \%)$ \\
\hline \multicolumn{2}{|l|}{ Other psychological disorders $(n=133)$} \\
\hline Yes & $9(11.5 \%)$ \\
\hline No & $69(88.5 \%)$ \\
\hline \multicolumn{2}{|l|}{ Physical problems ( $n=133$ ) } \\
\hline Yes & $33(45.2 \%)$ \\
\hline No & $40(54.8 \%)$ \\
\hline
\end{tabular}


Table 1

Sociodemographic characteristics and health conditions of family members who answered the proactive call $n=133$

3 of 3

\begin{tabular}{ll}
\hline Variables & $N(\%)$ \\
\hline Use of medications $(n=133)$ & $67(50.4 \%)$ \\
Yes & $66(49.6 \%)$ \\
No & \\
Antidepressant $(n=133)$ & $21(35.6 \%)$ \\
Yes & $38(64.4 \%)$ \\
No & \\
Anxiolytic $(n=133)$ & $16(27.1 \%)$ \\
Yes & $43(72.9 \%)$ \\
No & \\
\hline
\end{tabular}

Complaints related to damage to their own health were reported with the following frequencies: psychological problems (52.3\%), physical problems (29.5\%), and physical and psychological suffering (18.0\%). Having received a diagnosis of depression (53.4\%) among the most frequent psychological disorders.

Regarding codependent beliefs and behaviors during the monitoring of family members, there was a decrease in high codependency (Figure 2). The decrease was maintained in the proactive call, with only $35 \%$ of family members showing high codependency.

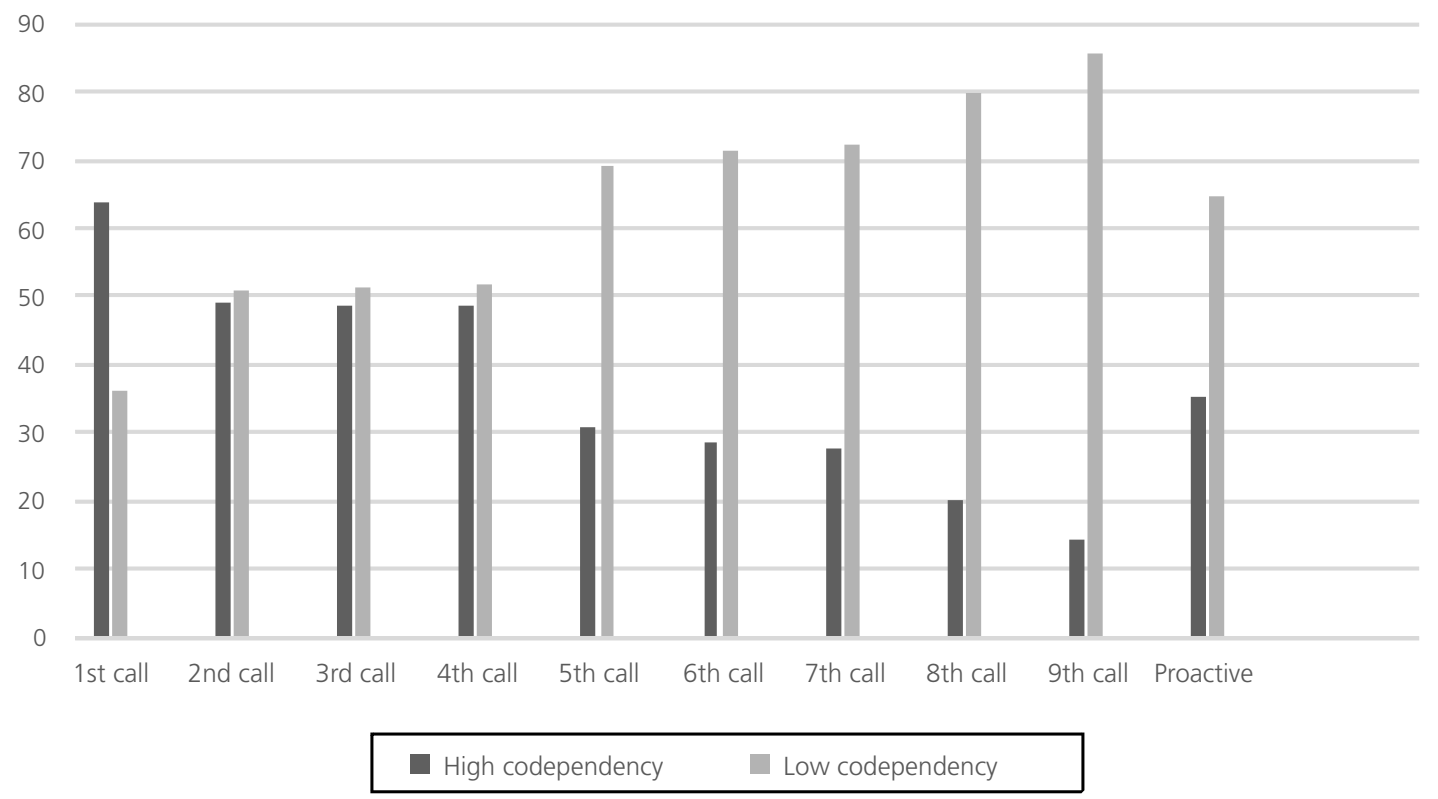

Figure 2. Percentage of family members with high and low codependency levels during the teleintervention.

As for the substance used by the individual, the most prevalent was alcohol (80\%), followed by tobacco $(62 \%)$, cannabis (45\%), crack (44\%), and cocaine (40\%). The use of alcohol showed statistical significance when associated with low follow-up adherence of family members ( $p=0.05$ ) (Table 2). 
Table 2

Factors related to psychoactive substances used by the individual that interfere in the adherence to the treatment of family members

\begin{tabular}{|c|c|c|c|}
\hline Variables & Low adherence & High adherence & $p$ \\
\hline \multicolumn{4}{|c|}{ Alcohol user $(n=133)$} \\
\hline Yes & 93 & 14 & $0.05^{*}$ \\
\hline No & 26 & 0 & \\
\hline \multicolumn{4}{|c|}{ Tobacco smoker $(n=133)$} \\
\hline Yes & 73 & 10 & 0.46 \\
\hline No & 46 & 4 & \\
\hline \multicolumn{4}{|c|}{ Cannabis (drug) smoker $(n=133)$} \\
\hline Yes & 54 & 6 & 0.85 \\
\hline No & 65 & 8 & \\
\hline \multicolumn{4}{|c|}{ Cocaine user $(n=133)$} \\
\hline Yes & 46 & 7 & 0.41 \\
\hline No & 73 & 7 & \\
\hline \multicolumn{4}{|c|}{ Crack user $(n=133)$} \\
\hline Yes & 53 & 5 & 0.52 \\
\hline No & 66 & 9 & \\
\hline \multicolumn{4}{|c|}{ Stopped using drugs nowadays ( $n=133$ ) } \\
\hline Did not stop & 60 & 8 & 0.71 \\
\hline Stopped & 38 & 4 & \\
\hline
\end{tabular}

Note: ${ }^{*} p<0.05$.

\section{Discussion}

Among the factors investigated, the type of the substance used by the individual proved to be an obstacle to adherence to the treatment of the family member. The use of alcohol showed significant interaction with the non-adherence of the family member. This finding corroborates a study that assessed the adherence of family members of alcohol users to face-to-face treatment and found a high treatment dropout rate (Arico, Zannero, Galatola, Valenti, \& Carrao 1994). The low adherence to the treatment of family members of alcohol users is related to the cumulative damage of the problem drug use developed in the family system, such as experiences of violence, social isolation, and the stigma related to the problem use of alcohol by the individual, in addition to the responsibility for the use of licit or illicit drugs that is transferred to the family member of this user, which results in the priority of meeting the user's needs, reducing the attention given to satisfaction and self-care (Tamutiene et al., 2016). Low adherence to treatment is also found in a study that investigated the adherence of alcohol users themselves to the treatment. This result was associated with low persistence in the therapeutic approach and the impulse to seek new strategies to deal with the problem use of alcohol, which results in low treatment effectiveness (Foulds, Newton-Howes, Guy, Boden, \& Mulder, 2017).

Another factor that can prevent adherence is the high codependency of family members when they make the first call to the hotline. Complaints of intense tiredness, sleep deprivation, and worrying, were symptoms reported by family members in this study and other reports (Bortolon et al., 2017; Lampis et al., 2017; Lima et al., 2019; Sakiyama et al., 2015), demonstrating the problems posed to these family members of problem drug users relatives and their suffering. Low adherence may be related to the characteristics of the codependency framework of these individuals, such as self-sacrifice, where family members neglect their own needs to prioritize the demands of the substance user (Askian et al., 2016; Silva et al., 2019; Vederhus et al., 2019).

In our sample, depression was the most frequent mental health problem of the codependent 8 individuals, but it was not associated with adherence to the teleintervention. Emotional overload, the severity 
of psychological symptoms, and the frequency with which the mental health issues were reported can be indicators of low adherence (Vederhus et al., 2019). It should be noted that depressive symptoms have been related, in the literature, to predictive factors for low adherence to treatments of other diseases (Arlt, 2017; Zielinski et al., 2019) and also for increased antidepressant treatment drop out (Rohden et al., 2017).

The result of the low adherence of family members to a telemedicine follow-up appointment, found in the present study, is in line with other studies (Bortolon et al., 2017; Moreira et al., 2014). The discontinuity of monitoring is already seen as a natural and typical feature of services that use technological advances to provide health care (Eysenbach, 2005). There are indications that this telephone-based intervention caused a significant decrease in the codependency levels. A significant number of the sample (77.4\%) decreased their codependency when comparing the scores of the first and last call, despite the low adherence to the treatment. It became evident that there is no clear association between decreased codependency levels and adherence.

The measurement of the adherence is a complex process (Arlt, 2017), without an established standard form. Several examples of behaviors prescribed by health care professionals aiming at the prevention of health problems, to reduce symptoms of diseases and to increase the effectiveness of interventions demand attending scheduled appointments and maintaining focus in compliance, which is difficult to be fully, consistently adherent for longer periods of time. These are some very important measures that lead to changing habits such as in: diets, physical exercises, safe sex, stop using psychoactive substances (Moreira et al., 2014) or making behavioral modifications that might lead that person to a better mental health. When considering the adherence process, in addition to the continuity of the calls, the assessment of the information and interventions within the therapeutic process, lead to a reduction in the codependency score, so the family members adhered to the motivational intervention for codependent behavioral changes, even without fully accessing these telephone calls. This result supports the findings of the effectiveness of Motivational Teleintervention in the treatment of codependent family members, as has been shown to be effective by changing the behavior of codependents in other studies, which resulted in twice as much chance of decreasing codependency scores, despite the dropout rate of $76 \%$ (Bortolon et al., 2017).

The guidance provided to codependent family members aims to assist them in understanding how the development of maladaptive beliefs and behaviors provides for the planning of behavioral changes that can assist these drug users in the process of quitting. This type of intervention is extremely important for the family to effectively assist the user.

Among the limitations of the study is the significant sample loss when monitoring participants, which may have interfered with the results of the study. Another limitation is that the interviews were conducted through proactive calls up to 3 years after the first contact, which may have caused memory bias. In addition, with the smaller sample, it was not possible to investigate the adherence of participants with different degrees of codependency. The lack of a control group is also a limitation of this study.

\section{Conclusion}

This study sought to investigate the possible factors that interfered in the adherence to the telemedicine procedure for family members of users of psychoactive substances. The use of alcohol by the individual was an important factor for low adherence. We conclude that the treatment dropout by codependent family members can be explained by the losses accumulated over a long period in the family system due to the problem use of alcohol. It is also necessary to consider that the non-adherence to the continuity of this treatment by family members is linked to the fact that he or she chooses and prefers to meet the needs of his or her son, husband, father / mother who is a user, neglecting his or her own care and need for attention. 
The findings of this study can be used in clinical contexts, highlighting with patients the importance of adherence to this treatment, after the diagnosis of codependency, with the patient leaving a passive role and becoming a participant in the treatment process, through psychoeducation. The study also highlights the greater attention that health care professionals and treatment centers need to have with family members of problem alcohol users. It is suggested that family members who follow the treatment of drug users participate in the diagnostic processes of codependency, so that the interventions offered in treatment centers are better monitored and productive.

\section{Contributors}

H. P. BAPTISTA contributed to the development of the project, data collection, analysis of the results and elaboration of the discussion and conclusion. C. B. BORTOLON contributed to data collection and discussion of the article. T. C. MOREIRA contributed to the development of the project, statistical analysis of the data, discussion of the results and elaboration of the discussion and conclusion. H. M. T. BARROS guided the dissertation that originated the present article, as well as contributed in the elaboration of the project, analysis of results and development of the discussion and conclusion.

\section{References}

Ahmad-Abadi, F. K., Maarefvand, M., Aghaei, H., Hosseinzadeh, S., Abbasi, M., \& Khubchandani, J. (2017). Effectiveness of satir-informed family-therapy on the codependency of drug dependents' family members in Iran: a randomized controlled trial. Journal of Evidence-Informed Social Work, 14(4), 301-310. https://doi.org/10.1080/23761407.201 7.1331147

Arico, S., Zannero, A., Galatola, G., Valenti, M., \& Carrao, G. S. (1994). Family compliance to a treatment programme for alcoholics: a prospective study of prognostic factors. Alcohol \& Alcoholism, 29(6), 679-685. https://doi.org/10.1093/ oxfordjournals.alcalc.a045603

Arlt, A. D. (2017). Why current drug adherence programs fail: addressing psychological risk factors of nonadherence. Current Opinion Psychiatry, 30(5), 326-333. https://doi.org/10.1097/YCO.0000000000000345

Askian, P., Krauss, S. E., Baba, M., Kadir, R. A., \& Sharghi, H. M. (2016). Characteristics of co-dependence among wives of persons with substance use disorder in Iran. International Journal of Mental Health and Addiction, 14, 268-283. https://doi.org/10.1007/s11469-016-9631-0

Barros, H. M. T., Santos, V., Mazoni, C., Dantas, D, C, M., \& Ferigolo, M. (2008). Neuroscience education for health profession undergraduates in a call-center for drug abuse prevention. Drug and Alcohol Dependence, 98, 270-274. https://doi.org/10.1016/j.drugalcdep.2008.07.002

Bortolon, C. B., Moreira, T. C., Signor, L., Guahyba, B. L., Figueiró, L. R., Ferigolo, M., \& Barros, H. M. T. (2017). Six-Month outcomes of a randomized, motivational tele-intervention for change in the codependent behavior of family members of drug users. Substance Use \& Misuse, 52(2), 164-174. https://doi.org/10.1080/10826084.2016.1223134

Dear, G., \& Roberts, C. (2005). The validation of the holyoake codependency index. Journal of Psychology, 139(4), 293313. https://doi.org/10.3200/jrlp.139.4.293-314

Eysenbach, G. (2005). The law of attrition. Journal of Medical Internet Research, 7(1), e11. https://doi.org/10.2196/ jmir.7.1.e11

Foulds, J., Newton-Howes, G., Guy, N. H., Boden, J. M., \& Mulder, R. T. (2017). Traços dimensionais de personalidade e resultado do tratamento com álcool: uma revisão sistemática e metanálise. Addiction, 112(8), 1345-1357. http:// dx.doi.org/10.1111/add.13810

Lampis, J., Cataudella, S., Busonera, A., \& Skowron, E. A. (2017). The role of differentiation of self and dyadic adjustment in predicting codependency. Contemporary Family Therapy, 39(1), 62-72. http://dx. doi.org/10.1007/s10591017-9403-4

Laranjeira, R., Madruga, C. S., Pinsky, I., Caetano, R., \& Mitsuhiro, S. S. (2014). II Lenad: levantamento nacional de álcool e drogas - Relatório 2012. São Paulo: INPAD. Disponível em: https://inpad.org.br/wp-content/uploads/2014/03/LenadII-Relat\%C3\%B3rio.pdf 
Lima, D. J. R., Sakiyama, H. M. T., Padin, M. F. R., Canfield, M., Bortolon, C. B., Mitsuhiro, S. S., \& Laranjeira, R. R. (2019). Characteristics of Brazilian women affected by a substance misusing relative. Journal of Addictive Diseases, 37(3-4), 1-5. https://doi.org/10.1080/10550887.2019.1637994

Machado, C. A., Moreira, T. C., Ferigolo, M., Oliveira, M. S., \& Barros, H. M. T. (2012). Envolvimento de clientes com diferentes formas de violência em um serviço de telemedicina para dependência química. Revista de Saúde Pública de Santa Catarina, 5(2), 22-29. https://doi.org/10.1590/S0101-81012008000400007

Moreira T. C., Signor, L., Figueiró, L. R., Fernandes, S., Bortolon, C. B., Benchaya, M, C., ... Barros, H. M. T. (2014). Non-adherence to telemedicine interventions for drug users: systematic review. Revista de Saúde Pública, 48(3), 521-531. https://doi.org/10.1590/S0034-8910.2014048005130

Morisky, D. E., Ang, A., Krousel-Wood, M., \& Ward, H. J. (2008). Predictive validity of a medication adherence measure in an outpatient setting. Journal of Clinical Hypertension, 10(5), 348-354. https://doi.org/10.1111/j.1751-7176.2008.07572.x

Oene, G. H. W., Burger, H., Grobbee, D. E., \& Schrijvers, A. J. P. (2007). Identification of patients at high risk of noncompliance in substance dependence treatment. European Addiction Research, 13(2), 74-80. https://doi. org/10.1159/000097936

Oliveira-Filho, A. D., Morisky, D. E., Neves, S. J. F., Costa, F. A., \& Lyra, D. P. (2014). Escala de adesão à medicação Morisky de 8 itens: validação de uma versão em português do Brasil em adultos hipertensos. Pesquisa em Farmácia Social e Administrativa, 10(3), 554-561. https://doi.org/10.1016/j.sapharm.2013.10.006

Panaghi, L., Ahmadabadi, Z., Khosravi, N., Sadeghi, M. S., \& Madanipour, A. (2016). Living with addicted men and codependency: the moderating effect of personality traits. Addiction Health, 8(2), 98-106.

Reiners, A. A. O., Azevedo, R. C. S., Vieira, M. A., \& Arruda, A. L. G. (2008). Produção bibliográfica sobre adesão/não-adesão de pessoas ao tratamento de saúde. Ciência \& Saúde Coletiva, 13(Supl. 2), 2299-2306. https://doi.org/10.1590/ S1413-81232008000900034

Rohden, A. I., Benchaya, M. C., Camargo, R. S., Moreira, T. C., Barros, H. M. T., \& Ferigolo, M. (2017). Dropout prevalence and associated factors in randomized clinical trials of adolescents treated for depression: systematic review and meta-analysis. Clinical Therapeutics, 39, 971-992. https://doi.org/10.1016/j.clinthera.2017.03.017

Sakiyama, H. M. T., Padin, M. F. R., Canfield, M., Laranjeira, R., \& Mitsuhiro, S. S. (2015). Family members affected by a relative's substance misuse looking for social support: who are they? Drug and Alcohol Dependence, 147, $276-279$. https://doi.org/10.1016/j.drugalcdep.2014.11.030

Silva, M. P., Oliveira, A. M. N., Silva, P. A., Algeri, S., \& Soares, M. C. F. (2019). Family orientation group as a strategy for care in chemical codependency. Investigación y Educación En Enfermería, 37(3), 1-9. https://doi.org/10.17533/ udea.iee.v37n3e08

Tamutiene, I., \& Laslett, A.-M. (2016). Associative stigma and other harms in a sample of families of heavy drinkers in Lithuania. Journal of Substance Use, 22(4), 425-433. https://doi.org/10.1080/14659891.2016.1232760

Ulusoy, Y., \& Guçray, S. S. (2017). Adaptation of composite codependency scale to Turkish: a validity and reliability study. Journal of International Social Research, 10(49), 373-379.

United Nations Office on Drugs and Crime. (2017). Word Drug Report. Austria: UNODC. Retrieved from http://www.unodc. org/lpo-brazil/pt/frontpage/2017/06/cerca-de-29-5-milhes-de-pessoas-em-todo-o-mundo-sofrem-de-transtornosprovocados-pelo-uso-de-drogas--os-opiides-so-os-mais-prejudiciais_-aponta-relatrio-mundial-sobre-drogas-2017-dounodc.html https://doi.org/10.18356/c595e10f-en

Vederhus, J., Kristensen, O., \& Timko, C. (2019). How do psychological characteristics of family members affected by substance use influence quality of life? Quality of Life Research, 28, 2161-2170. https://doi.org/10.1007/s11136-01902169-x

Zielinski, M., Bradshaw, S., Mullet, N., Hawkins, L., Shumway, S., \& Chavez, M. S. (2019). Codependency and prefrontal cortex functioning: preliminary examination of substance use disorder impacted family members. American Journal on Addictions, 28(5), 1-9. https://doi.org/10.1111/ajad.12905

World Health Organization. (2003). Adherence to long-term therapies: evidence for action. Geneva: Author. Retrieved from http://www.who.int/chp/knowledge/publications/adherence_report/en/

Received: March 19, 2020

Final version: July 7, 2020

Approved: September 9, 2020 